An empirical analysis of supply and manufacturing risk and business performance: A Chinese manufacturing supply chain perspective

Vikas Kumar ${ }^{1}$, Ozlem Bak², Ruizhi Guo ${ }^{3}$, Sarah Shaw ${ }^{4}$, Claudia Colicchia ${ }^{4}$, Jose Arturo Garza-Reyes ${ }^{5}$, Archana Kumari ${ }^{1}$

${ }^{1}$ Bristol Business School, University of the West of England, UK

${ }^{2}$ Brunel Business School, Brunel University London, UK

${ }^{3}$ Warwick Manufacturing Group, University of Warwick, UK

${ }^{4}$ Hull Business School, University of Hull, UK

${ }^{5}$ Derby Business School, University of Derby, UK 


\title{
An empirical analysis of supply and manufacturing risk and business performance: A Chinese manufacturing supply chain perspective
}

\begin{abstract}
Purpose - This study explores the importance and impact of supply and manufacturing risk management upon business performance within the context of Chinese manufacturing supply chains.

Design/Methodology/Approach - A two phased multi-method approach was adopted, which included a survey questionnaire to practitioners in Chinese manufacturing supply chains followed by semi-structured interviews. The findings included 103 valid survey responses complemented by six semi-structured interviews.

Findings - The results indicate that in Chinese manufacturing context supply risk and manufacturing risk management are both vital for business performance. A high correlation between business and manufacturing risk management performance exists, however no significant impact of supplier dependency, systematic purchasing, maturity of production and supply chain, and human resources was found despite previously these elements being regarded as key influencers for supply and manufacturing risk management performance. The Chinese manufacturing supply chain indicated that elements such as the supplier and customer orientation, flexibility, manufacturing and supply risk highly connotes with business performance.
\end{abstract}

Theoretical/Practical implications - In the current unpredictable and volatile business environment the competitiveness of manufacturing supply chains to a large extent depend on their ability to identify, assess and manage the manufacturing and supply risks. The findings of this study will assist supply chain managers in taking decision on manufacturing and supply risk management and reducing the uncertainty upon their business performance.

Originality/value - The supply chain risk has been widely explored within the context of individual case studies, or standalone models focusing on either supply or manufacturing risk in supply chains, however to what extent this has been applicable to a wider context and its impact upon business process has not been explored. Hence, this study simultaneously has analysed manufacturing risk and supply risk and its impact upon Chinese manufacturing supply chains business performance. Moreover, this study uses a combination of quantitative and qualitative methods, which is often limited in this area. Finally, the institutional theory lens offers novel insights in better understanding the factors that can affect the impact of supply and manufacturing risk management upon business performance in those contexts, such as China, where the institutional aspect presents specific features.

Keywords - Institutional Theory, Supply Chain Management, Supply Chain Risk, China, Manufacturing Risk, Supply Risk, Business Performance,

Article Classification - Research paper 


\section{Introduction}

The growing scale and scope of supply chain architecture has brought various risks influencing an organization's capability to operate continually and provide goods and services to the market (Jordan and Bak, 2016). According to the Business Continuity Institute (BCI) $81 \%$ of international enterprises suffered at least one supply chain disruption in 2013 compared to $78.6 \%$ in 2010 (Alcantara, 2014) indicating that the disruption of supply chains around the world has reached a pervasive level. Some wellknown examples of such incidents are Ericsson's crisis in 2000, the 9/11 terrorism event in 2003 and the tsunami in Japan affecting Toyota in 2011 (Jüttner et al., 2003; Sun et al., 2012; Ho et al., 2015). Considering that approximately $20 \%$ of supply chain disruptions are experiencing a financial loss of over $\$ 500$ million with a potential of $25 \%$ average decrease of share prices, reflects that firms who experience supply chain disruption are likely to suffer long-term impact on financial performance (Conrad and Walker , 2012; Sun et al., 2012).

Therefore, identifying the inherent supply chain risks is a core activity since it allows managers to understand risk better and improve the management of supply chain risks (Lin and Zhou, 2011). From a supply chain managers' perspective it is difficult to justify the investments made on risk mitigation initiatives if they are not directly related to the payoff (Rajagopal et al., 2017). In order to overcome the idea that "nobody gets credit for fixing problems that never happened" (Repenning and Sterman, 2001: 64) and to promote supply chain risk management (SCRM) best mitigation practices, the relation between the actions taken and the impact on the business performance needs to be investigated (Colicchia and Strozzi, 2012). However, only few contributions have empirically investigated the relationship between supply chain risk and performance. Furthermore, the supply chain risk has been widely explored within the context of individual case studies, or standalone models, while the research on multiple supply chain risks and their simultaneous impact on business performance through empirical research are limited. As advocated by Ho et al. (2015), further investigations on the interrelationships among different types of risk rather than standalone risks would better support SCRM decision-making process.

Supply and manufacturing risks gained increasing attention due to the high connectivity of supply chains. Supply chains in fact are increasingly operating in networked and global environment, where the ability to build and maintain relationships with suppliers is equally 
critical and challenging for businesses (Hallikas and Lintukangas, 2016). For example, the outsourcing of non-core activities to suppliers and service providers increases firms' dependency on external resources (Bustinza et al., 2010), and it is widely acknowledged that purchasing can heavily affect business performance (Hallikas and Lintukangas, 2016; Aberdeen Group, 2013). The volatility in purchasing can lead to risks of product obsolescence, investment in capital assets and high inventory level. Hence, supply risk is closely connected to manufacturing risk that can affect the ability of the focal company to produce high quality goods and services in a timely manner and, in turn, achieve profitability (Ho et al., 2015).

According to Eloot et al. (2013) the manufacturing sector accounted for $40 \%$ of China's gross domestic product (GDP) in 2013, which led to new supply chain risk exposure due to four major challenges: the rising labour cost, the shift in consumer expectations towards product quality, innovation, and service, the increase of value chain complexity and the volatile global economic environment (Eloot et al., 2013). Previous research has investigated the contextual risks associated with outsourcing activities to China's manufacturers (Huang, Zhang and Liu, 2013; Jia and Rutherford, 2010; Olson and Wu, 2011; Kumar and Sosnoski, 2009). Jia and Rutherford (2010) argue that cultural difference is a critical factor contributing to the supply risks in the business between western purchasing companies and Chinese suppliers. They suggest that understanding the cultural difference and adopting cultural adaptation are crucial to mitigate the related risks. More recently, Ellinger et al. (2015) highlight that research examining cultural and behavioural factors that may improve SCRM practice is still scarce.

A survey conducted by Marchese and Paramasivam (2013) indicated that China is regarded as a costly source of adverse outcomes from risk events in the supply chain, following the United States and Canada. When it comes to investigations concerning SCRM in Chinese manufacturing, the attention from researchers increases significantly due to the rapid growth of China's economy (Olson and Wu, 2010). However, the current studies on SCRM in the Chinese manufacturing sector are still scarce (Special issue on SCRM in China, 2009). Moreover, most recent literature investigated SCRM in Chinese manufacturing firms from a perspective of purchasing or outsourcing (Huang, Zhang and Liu, 2013; Jia and Rutherford, 2010; Olson and Wu, 2011; Kumar and Sosnoski, 2009) or investigated risk mitigation strategies (Liu et al., 2007). 
Therefore, the primary aim of this paper is to investigate supply and manufacturing risk management simultaneously and the impact upon business performance. The case of Chinese manufacturers will be explored since it represents a relevant and overlooked context as "companies operating in such weak institutional environments face many risks which can disrupt... operations" (Ke et al., 2014:1591). In fact, it is acknowledged that there is a relationship between a firm and the institutional environment in which it operates, as this latter shape the guiding principles of the company and the way it complies with external rules, norms, and values (Oliver, 1991). This applies to a context, like the China, where culture and other national characteristics play a relevant role in shaping business practices and affecting related performance (Adebanjo, Teh and Ahmed, 2017). Although research has indicated that weak institutional environments have an impact upon agricultural supply chains and their performance (Yeboah et al., 2014), the choice of Chinese manufacturers context may also provide an understanding of weak institutional environment and its association to supply chain risk to achieve better performance in China. Hence, we adopt institutional theory as a lens to help understand and contextualise the study's findings and to see if there are any 'influencing factors' which are unique to China that may affect the relationship of how these two variables impact business performance.

\section{Theory and hypotheses: Supply and Manufacturing Risk Management Performance}

Supply chain risk is a broad concept that offers a variety of risks, and presents a variety of methods for classification. Ho et al. (2015) propose a useful classification that takes account of both comprehensiveness and varieties of impact degrees: (a) macro risks are akin to environmental risks, the factors include natural and man-made disasters such as earthquakes, wars and economic downturns, and (b) micro risks are classified to four categories; demand risks, manufacturing risks, supply risks and infrastructure risks (Figure 1). 


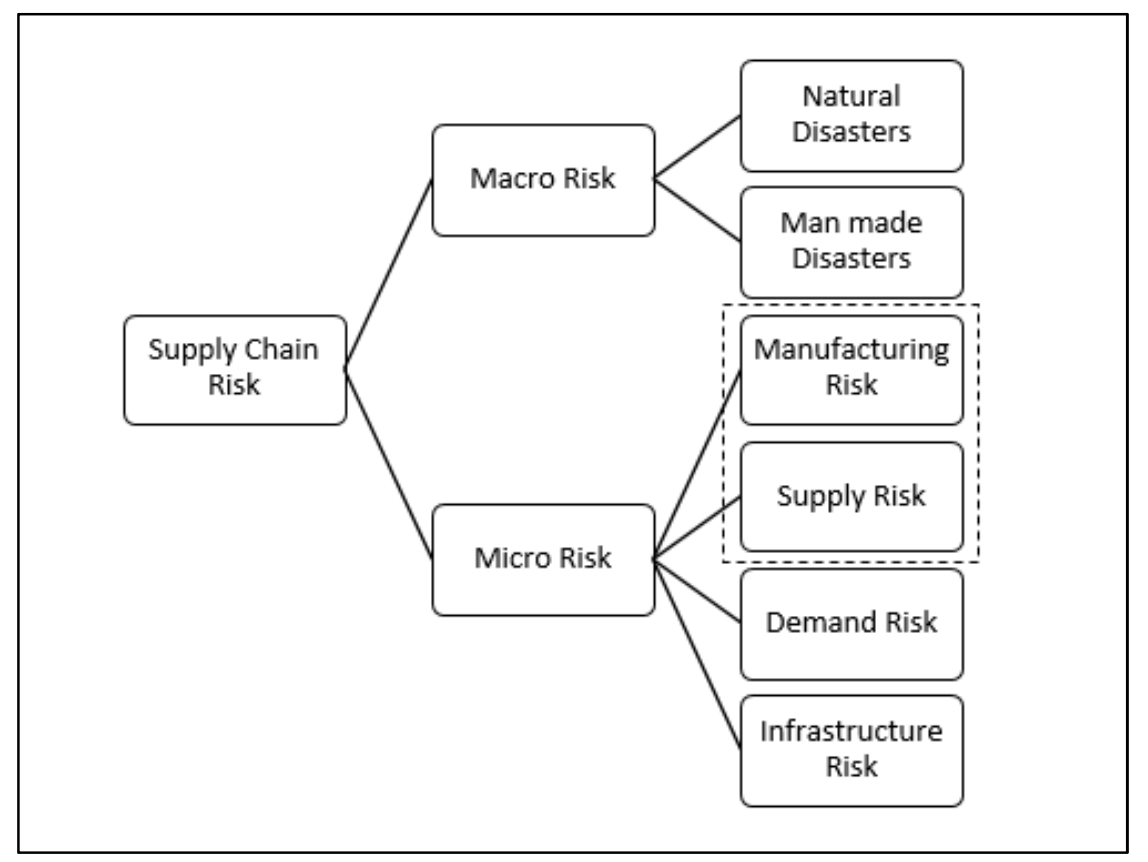

Figure 1: Classification \& Scope of Supply and Manufacturing Risk (Ho et al., 2015)

Among different types of risks, in the last decade, the changing economic landscape and supply chain structure have brought many supply and manufacturing risks (Manyika et al., 2012). Supply risk can be defined as "the probability of an incident associated with inbound supply from individual supplier failures or the supply market occurring, in which its outcomes result in the inability of the purchasing firm to meet customer demand or cause threats to customer life and safety" (Zsidisin, 2003, p.222). Manufacturing risk refers to factors and events that affect the ability of companies to produce goods and services, quality and timeliness of production activities, and profitability (Wu et al. 2006). A number of contributions have focused on the assessment and management of supply and manufacturing risks. For instance, Zsidisin et al. (2004) present a framework of supply risk assessment techniques, while Tomlin (2006) investigates strategies for managing supply risk through an analytical model. Tse and Tan (2011) propose a framework for assessing product quality risk in a multi-tier global supply chain, in which the quality risk could stem from supply, manufacturing or logistics operations in any tier within supply chain network. Tang (2006) claims that the key concern of supply chain risk regarding product manufacturing is to decrease the inventory cost associated with a certain range of products.

As mentioned above, it is essential for firms to measure the outcomes of supply chain risk practices. Berg et al. (2008) noted that measurement of performance allows companies to assess the result of practices carried out. For managers, this understanding of associated 
supply chain risk would allow them to adopt specialized strategies for specific types of risk (Ho et al., 2015). Nagy and Venter (2011) propose an approach to measure supply chain performance with the following metrics: the proportion of supply chain related costs/overall sales revenue, customer satisfaction level and customer service level. By contrast, PwC (2015) covers three main categorizations of business performance: profitability, efficiency and service.

With the current studies concentrates on general supply chain risks (Qiang et al., 2014; Tang and Tomlin, 2008; Brun et al., 2006; Christopher and Lee, 2004) and specific risk types (Ellinger et al., 2015; Tang et al., 2012), only a few studies focused on two risk types simultaneously (Ho et al., 2015; Baghalian, Rezapour, and Farahani 2013; Qiang and Nagurney 2012; Goh et al., 2007). indicating a lack of investigation on the relationship between risk management and performance (Sun et al., 2012; Berg et al., 2008) with most of the literature regarding this relationship based on conceptual rather than empirical studies (Hallikas and Lintukangas, 2016; Thekdi \& Aven, 2016). Table 1 presents a summary of the supply and manufacturing risk and respective performance areas in supply chain literature.

Table 1 Categories of supply and manufacturing risk performance from supply chain management literature

\begin{tabular}{|c|c|}
\hline SCRM performance areas & Authors \\
\hline Supply risk management performance & $\begin{array}{l}\text { Hoffmann et al., 2013; Hallikas and Lintukangas, 2016; } \\
\text { Ho et al., 2015; Indrawati et al., } 2014\end{array}$ \\
\hline Supplier orientation & Cigolini and Rossi, 2010; Bronzo et al., 2013 \\
\hline Supplier dependency & $\begin{array}{l}\text { Aberdeen Group, 2013; Hallikas and Lintukangas, 2016; } \\
\text { Zhao et al., 2013; }\end{array}$ \\
\hline Systemic purchasing & $\begin{array}{l}\text { Hallikas and Lintukangas, 2016; Epp and Price, 2011; } \\
\text { Aberdeen Group, } 2013\end{array}$ \\
\hline Customer orientation & Hallikas and Lintukangas, 2016; Zhao et al., 2013 \\
\hline \multicolumn{2}{|l|}{ Maturity of SCM process } \\
\hline & $\begin{array}{l}\text { Hoffmann et al., 2013; Ho et al., 2015; Indrawati et al., } \\
\text { 2014; Isoherranen et al., } 2015\end{array}$ \\
\hline Firm size & Hallikas and Lintukangas, 2016 \\
\hline Culture & Jia and Zsidisin, 2014; Cheng et al., 2012 \\
\hline Manufacturing risk management performance & $\begin{array}{l}\text { Lamarre et al., Be et al., 2015; Hong et al., 2014; Ellinger } \\
\text { et al., 2015; Cheng et al., 2012; Jia and Zsidisin, 2014; Li } \\
\text { et al., } 2015\end{array}$ \\
\hline Production Flexibility & $\begin{array}{l}\text { Hoffmann et al., 2013; Isoherranen et al., 2015; Harrison, } \\
2014\end{array}$ \\
\hline
\end{tabular}




\begin{tabular}{ll}
\hline Maturity of manufacturing process & Hallikas and Lintukangas, 2016; Hoffmann et al., 2013; \\
& Ho et al., 2015; Indrawati et al., 2014; Isoherranen et al., \\
& 2015 \\
HR management & Yeung, 2012; Cheng et al., 2012 \\
\hline
\end{tabular}

Understanding how China manages and responds to supply and manufacturing risk will have a significant impact on global trading, especially considering that China has been reported to account for one-fourth of the global gains on the import side and $30 \%$ on the export side (Hillberry \& Zhang, 2018). Athukorala (2011) noted that LPI is also a useful measure to consider as it ranks 160 countries and focuses on trade-related logistics provisions. According to the LPI, ranking China positioned itself on 27th position, moving towards ease of trades compatible to European counterparts such as Spain (World Bank, 2016).

A plethora of studies have uncovered differences in the cultural and society contexts of Chinese organisations compared to their Western counterparts and impacts on organisational/management practices (Chen et al., 2015; Farh et al., 2004; Ma and Tsui, 2015). Very little however, if any, have attempted to do so in terms of supply and manufacturing risks simultaneously, and their impact on business performance. Hence, we would like to understand how 'guanxi' and other cultural/institutional pressures, that are unique to China, may affect how supply and manufacturing risk impacts business performance in this context.

As noted by Zsidisin et al. (2005), a firm is constrained and influenced by the environment in which it operates within. Thus, how Chinese manufacturing firms respond to and are influenced by supply and manufacturing risk may be different to other country contexts. Hence, the institutional theory provides a useful lens in which investigate these country contextual issues, examining how external and internal pressures can influence organizational actions and performance (Sarkis et al., 2011). Although supply chain risk literature embedded the use of institutional theory (Zsidin et al., 2005; Wang et al., 2015; Su et al., 2008), these studies focused only on single activities in the Chinese context (Su et al., 2008; Liu et al., 2010). Therefore, the inclusion of a quantitative survey of manufacturing firms in China provides a richer context in terms of institutional theory and its practice. With this understanding the following hypotheses were developed.

Supply risk management performance 
According to Hoffmann et al. (2013: 200) "the development of ....supply risk management procedures and capabilities is proposed to increase supply risk management performance". Although the relationship between supply risk and performance observed, there are different risk factors associated with supply and manufacturing risk (Hoffmann et al., 2013; Hallikas and Lintukangas, 2016; Ho et al., 2015; Lamarre et al., 2009). For instance, upstream supply risks in a global supply chain, within China, who is a major product manufacturer and exporter, could result in disruptions affecting the manufacturing process (both in China and elsewhere), such as supplier bankruptcy and product quality issues and will thus affect the availability of inventory for manufacturing, leading to customer delivery failures and stock outs further down the supply chain, for instance in the UK, US or Europe consumer markets (Huang et al., 2013; Jia and Rutherford, 2010). In contrast, downstream supply risks, such as the inability to deliver on time, resulting from long supplier lead times, may result in a high level of inventory holding cost within the manufacturing process. In addition, technological changes in manufacturing may contribute to an inability to meet customer delivery requirements. In addition, the differences between industry sectors and their contextual settings have an impact upon the supply risk and its business performance (Bak, 2018; Ho et al., 2015). Therefore:

\section{H1 Supply risk management performance within a Chinese manufacturing context influences business performance}

\section{Manufacturing risk management performance}

According to Das and Lashkari (2015), manufacturing risk is of critical importance since it is under the control of the company, and can involve factors and events that affect the ability of companies to produce goods and services, quality and timeliness of production activities, and profitability (Wu et al., 2006). Previous studies indicated that manufacturing risk has significant impact upon supply chain performance (Li et al., 2015; Ellinger et al., 2015; Hong, Kwon and Li, 2014; Cheng et al., 2012; Jia and Zsidisin, 2014). A number of contributions have focused on the assessment and management of manufacturing risks (Zsidisin et al., 2004; Kwon and Li, 2014; Tomlin, 2006). However, there is limited understanding on the impact on performance in the Chinese manufacturing industry context. In this context, given the challenges faced by the manufacturing sector and the key role played by manufacturing and export for China's competitiveness, the research identified a high correlation between manufacturing risk management and business 
performance (Ellinger et al., 2015; Li et al., 2015). Especially, from an institutional theory perspective, it is also important to understand how China, one of the biggest exporters, manages and responds to manufacturing risk, as this will have a significant impact on global trading. Similarly, Liu et al. (2007) identified the risks in Chinese manufacturing industry and proposed corresponding mitigation strategies whilst taking account of the cost, which could assist supply chain organizations to select appropriate mitigation strategies with less cost. Hence, we hypothesise that:

\section{H2 Manufacturing risk management performance influences business performance within a Chinese manufacturing context}

\section{Supplier orientation}

Supplier orientation refers to the relationship between customer and supplier and can have positive impact on the management of disruptive risks. For instance, during the 9.0magnitude earthquake in Japan in 2013, the production of Nissan Motor Company Ltd and its suppliers recovered from the disaster much faster than their competitors did. One of the key factors to Nissan's strong resilience in the supply chain was the flexible supply chain model structure. The flexibility and close orientation with suppliers allowed its supply chain structure to be decentralized and transfer to centralization when required $(\mathrm{PwC}$, 2015). However, supplier orientation is also directly linked to the development of relationships with suppliers, including the integration of the information and physical flows across the supply chain enabling collaborative planning and forecast with suppliers for joint plans for process improvement (Bronzo et al., 2013). Hong, Kwon and Li (2014) claim that the perception of partnership and risk has significant impact on business performance. Studies also highlight that specific risk setting -such as guanxi in China - can affect the performance of SCRM (Jia and Zsidisin 2014; Cheng et al., 2012). Jia and Zsidisin (2014) claim that the supply chain relationship management with guanxi is prominent for western firms to manage the risks among the outsourcing activities to China. Hence, Hallikas and Lintukangas (2016) suggest that supplier orientation is based on the theory that supplier-development activities can positively influence supply chain management. It mainly concerns the collaboration with suppliers in the field of evaluation, common goals, new collaboration space and formulating joint business processes. From a Chinese manufacturing perspective, the guanxi culture and importance on relationships in Chinese business (Wang et al., 2015) may have an impact on supplier orientation and on 
supply risk management. Furthermore, from an institutional theory perspective, isomorphic pressures may affect how Chinese manufacturers orient with their suppliers. Therefore:

\section{H3 Supplier orientation in a Chinese manufacturing context influences the result of supply risk management}

\section{Supplier dependency}

Supplier dependency means supplier's reliance on a customer in a deeper relationship or vice versa. Some customers may choose to place all of their business with one supplier, while others will dual, triple or use multiple sources. Dependency on sole suppliers, while it allows for developing deep relationships and potential integration with the aim to manage risks in the supply chain, on the other hand it can expose businesses to higher levels of risk related to the availability of sourced materials. In addition, the dependency on sole suppliers, who are contractually bound, can mean increased transaction costs, which in turn lead to an increase in the cost of raw materials for manufacturing, generating risk and affecting customer satisfaction and market share (Hallikas and Lintukangas, 2016). Other risks generated from supplier dependency include nonconformity or quality issues of products from suppliers, which may result in manufacturing incidents. The manufacturing incidents with supply chains are getting more complex, bringing a high level of interdependency requiring the assessment of the performance (Bak, 2018). After the 2008 recession when the economy recovered, many western companies, which relied solely on Chinese manufacturers, expected the same from Chinese manufacturers, to resume at the previous manufacturing capacity levels, but they discovered that China has reduced capacity to export in these areas. This resulted in major supply issues for developed nations. This represents a good example of how isomorphic pressures, such as a coercive force by the Chinese government, can influence supply chain risk in global supply chains. Therefore, we can hypothesise that:

H4 Supplier dependency in a Chinese manufacturing context influences the result of supply risk management

\section{Systemic purchasing}

Systemic purchasing means to purchase potentially diverse products and services in an integrated manner, in order to achieve efficient and economic targets. Disruptions from 
purchasing can affect supply chain financial performance and can cause disruptions in production (Hallikas and Lintukangas, 2016; Aberdeen Group, 2013). Hallikas and Lintukangas (2016:492) pinpoint the interconnectedness of purchasing performance and SCRM by iterating that "...suppliers in a buyer company increases its ability to perform risk management in its purchasing function." The understanding that systematic purchasing is interrelated to supply risk performance has been noted by Kamann et al. (2016:155) stating that " "purchasing' has transformed into an aspect-system connecting or involving all sub-systems [of supply chains]". Similarly, Hallikas and Lintukangas (2016) also found that there was a significant positive correlation between supply risk performance and systemic purchasing. However, they also acknowledge the presence of very limited empirical research in the systemic purchasing arena (Hallikas and Lintukangas, 2016). The above discussion leads us to propose the following hypothesis:

H5 Systemic purchasing within a Chinese manufacturing context influences the result of supply risk management

\section{Customer orientation}

Customer orientation can effectively reduce manufacturing risks such as product obsolescence. Moreover, customer value orientation is still essential for the supply chain to perform proactively in identifying customer needs and adapting rapidly to changes (Hallikas and Lintukangas, 2016; Reiner, 2005). For instance, by working closely with customers and understanding their business better, such as customer seasonal demand, new customer onboarding, mergers and acquisitions, new product introductions, suppliers can flex their operation, plan and meet the customer's expectations. The world recession of 2008 is a great example of this. In fact, when customer demand fell during the recession, many of the Chinese factories were closed and workers were incentivised by government to work in agriculture to support the economy. The customer orientation and activities involved creating collaborative platforms to potentially mitigate the risks (Christopher and Peck, 2004). Therefore:

H6a Customer orientation influences the result of supply risk management

$H 6 b \quad$ Customer orientation influences the result of manufacturing risk management 
Hoffmann et al. (2013) indicated that the SCRM process has the strongest positive influence on the performance of SCRM. From a holistic perspective of the supply chain any disruption in either supply or manufacturing will impact overall supply chain (Ho et al., 2015; Indrawati et al., 2014). Furthermore, as asserted by Isoherranen et al. (2015) process maturity is vital for manufacturing firms to achieve operational excellence, as the maturity level of processes has significant impacts on risk management. For instance, automation in manufacturing has numerous advantages, such as: improving quality, reducing dependency on labour and improving safety, which reduce the risk of product quality and production disruption (Harrison, 2014). Therefore, we can hypothesise that:

\section{H7a Maturity of SCRM process influences the result of supply risk management \\ $H 7 b \quad$ Maturity of SCRM process influences the result of manufacturing risk management}

\section{Production Flexibility}

Lamarre et al. (2009) stressed that production flexibility is a critical component for organizations in responding to the changing environment and mitigate the related manufacturing risk. Their study indicated that flexibility can be presented in four forms: the ability to adjust the capacity according to demand and profitability; the ability to alter the production capacity to fulfil product diversity; the capability to shorten lead times or to postpone production as a response to competitors; the ability to allocate the production in different nations or facilities, in order to achieve low cost or avoid risks such as strikes. This theory concentrates on risks related to productivity, market, labour, inventory factors. Nevertheless, it does not concern the factors such as technology, design and quality. Production flexibility can be enhanced by better collaboration, communication and coordination in the supply chain, which can, help to avoid scenarios such as excess stock in the supply chain generated by the bullwhip effect (Datta and Christopher, 2011). Therefore, we can hypothesise that:

\section{H8 Production flexibility influences the result of manufacturing risk management}

\section{Maturity of manufacturing process}

Hoffmann et al. (2013) noted that the maturity of SCRM process has vital impact on the performance of SCRM. A mature risk management process means the processes need to be well established, defined and controlled, as without developed processes, the risk 
management actions are likely to be spontaneous and non-systematic. Isoherranen et al. (2015) noted that mature manufacturing processes can positively improve firms' operational performance, which include managing manufacturing risks. The maturity of the manufacturing process refers to perfect procedures, adoption of advanced information technology (IT) software and automatic production. Harrison (2014) asserts that automation can efficaciously reduce risks from production, such as quality issues, dependency on labour and safety issues. Therefore, the above discussion leads us to propose that:

H9 Maturity of the production process influences the result of manufacturing risk management.

\section{Human Resource (HR) management}

People are one of the key ingredients for a supply chains' performance and can play a vital role in managing and mitigating supply chain risk. Thus, how people are managed through human resource (HR) processes (training, performance incentive, KPIs, disciplinary procedures) will have an impact on business performance (Mangan and Christopher, 2005). Furthermore, labour factors, incidents or situations, such as employee strikes, accidents, absence and lack of experience can influence supply chain performance. Therefore, it can be assumed that within a Chinese manufacturing context:

H10 HR management influences the result of manufacturing risk management

\section{Firm Size}

Firm size is regarded as a factor influencing corporations' risk management performance as large-scale enterprises are found to be performing better in distributing information and utilizing knowledge (Hallikas and Lintukangas, 2016). The firm size is considered as a main factor impacting an enterprise's risk management capability, since large organizations are found to have better information distribution and perform better in utilizing knowledge (ibid). Therefore, it is proposed that within a Chinese manufacturing context:

H11a Firm size influences the result of supply risk management

$H 11 b$ Firm size influences the result of manufacturing risk management 


\section{Culture}

Li et al. (2015) assert that supply chain relationships are essential in enhancing risk information sharing and risk sharing mechanism, which are vital SCRM practices affecting the financial performance of the supply chain. Cultural differences are widely recognized to have influence on business performance (Jia and Zsidisin, 2014; Cheng et al., 2012). According to Cheng et al. (2012), Chinese culture characteristics such as guanxi (guanxi refers to relationships in Chinese culture) might have an impact on the performance of management of supply chain risk. Guanxi can be utilized to promote the effectiveness of communication and trust in supply chain relationships, which will result in reducing supply chain risks. Since China has its distinctive culture influencing the relationship as well as communication in supply chain management, it is proposed within a Chinese manufacturing context that:

H12a Culture influences the result of supply risk management.

$H 12 b$ Culture influences the result of manufacturing risk management.

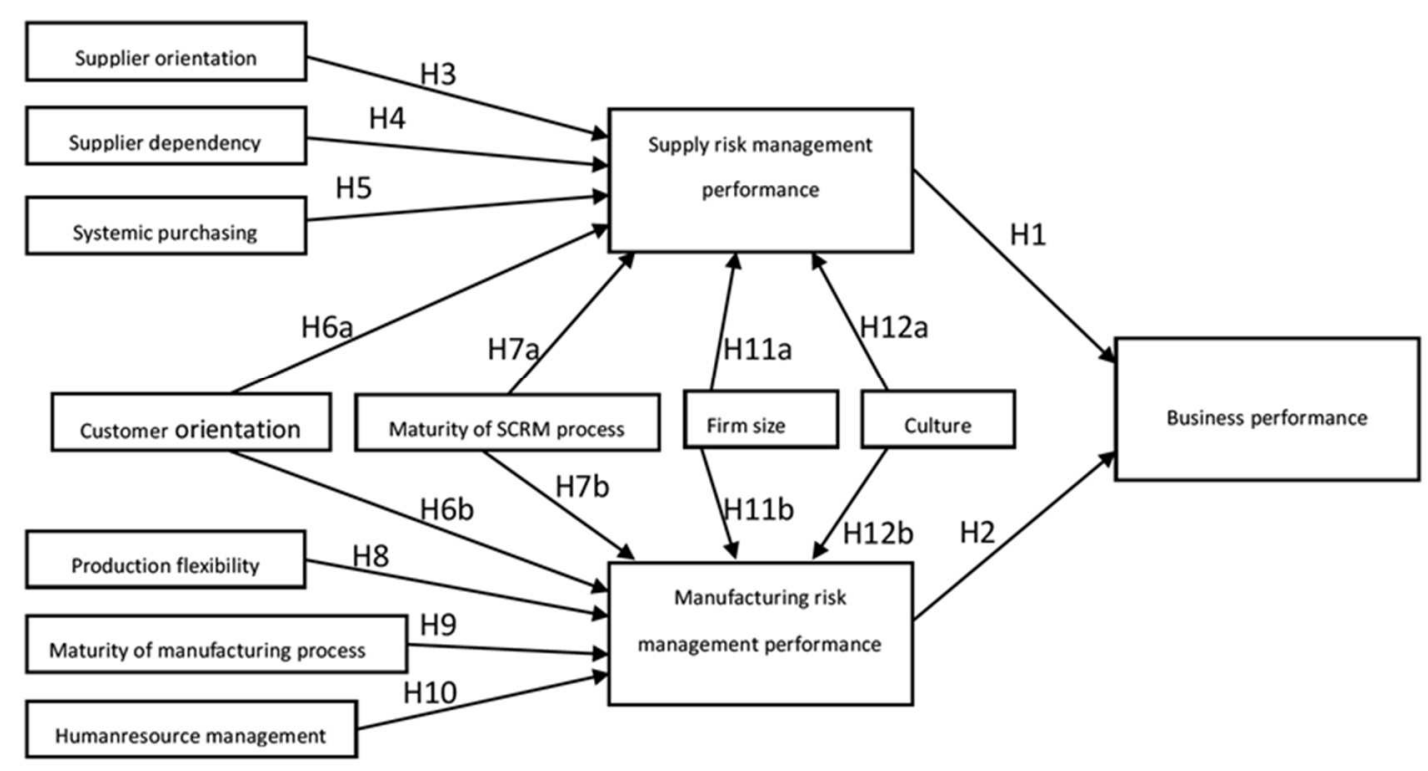

Figure 2. Conceptual Framework

\section{Methodology}

To assess the impact of supply and manufacturing risk on business performance and to achieve an in-depth understanding of the research issue (Mangan et al., 2004), this study 
adopts a mixed methods based approach. The first phase of the study was deductive involving a survey questionnaire issued to chief executive officers, managing directors, general managers and senior supply chain practitioners through personal contacts and LinkedIn. Whereas, the second phase of the research was inductive and involved six semistructured interviews with Chinese manufacturers to explore and explain the results emerged from the first phase.

The target population included all manufacturing firms within China. Since there are thousands of manufacturing enterprises in China, there are different perspectives of determining sample size from several authors. Based on the conceptual framework (Figure 2) developed in the literature review, a structured survey questionnaire with closed questions was adopted following Dillman et al. (2009)'s guideline. The questionnaire was also developed following the work of Wieland \& Wallenburg (2012) and Hallikas \& Lintukangas (2016) .The survey questionnaire was pilot tested prior to issue (see Appendix A in supplementary material).

In total 353 respondents from Chinese manufacturing organizations were contacted to complete the survey., which resulted with 103 valid responses, a response rate of $29 \%$. Although the sample size of 103 is relatively small, many studies have indicated that achieving high responses is always challenging and have hence reported lower survey responses (Freise and Seuring, 2015; Trkman, Oliveira and McCormack, 2016; Sharma and Bhat, 2014). For instance, Freise and Seuring (2015) used a survey of 92 companies to investigate social and environmental risk management in supply chains. A study by Trkman, Oliveira and McCormack (2016), used a combination of six case studies and a survey of 89 companies to conduct the study of value-oriented SCRM. Hence, the shortage of samples can be compensated by using combination of methods. In this study, to compensate for the smaller questionnaire sample, six semi-structured interviews were conducted to ensure theory saturation (Strauss and Corbin, 1994). Six respondents from six manufacturing companies were randomly selected as a subset of the survey questionnaire sample to interview. This enabled the researcher to gain an insightful understanding of the problem and to validate the survey questionnaire results. The respondents included a supply quality engineer, two planning managers, two purchasing managers and a project manager from two small, two medium and two large Chinese manufacturing businesses. The different job functions of the interviewees provided different perspectives toward the research under investigation. The data from the 
interviews were audio recorded, transcribed and coded into themes according to the research objectives.

\subsection{Scale development}

Multiple items were used for the measurement of each of the constructs, as summarized in Table 1, with constructs being defined based on literature review (Wong et al., 2012). Second, measurement items were generated which captured the construct as defined by using a panel of five expert academics in the field of supply chain management was consulted. For quantitative data analysis, Pallant (2010) noted that it is important to examine the reliability of scales. For scales, the reliability mainly concerns their internal consistency, which refers to the degree of accordance of items that make up the scales.

To measure the reliability of the scales Cronbach alpha test was conducted. The value of Cronbach alpha was over 0.7 , with the highest value of 0.932 and least value of 0.765 (Table 2). To test the convergent validity and discriminant validity, we have computed Average Variance Explained (AVE), Composite Reliability (CR), Maximum Shared Variance (MSV), and Average Shared Variance (ASV). For convergent validity, AVE should be $>0.5$ and the Composite Reliability (CR) should be $>.70$. As evident from Table 2, AVE values for all the constructs were higher than 0.5 and $C R$ values are higher than 0.70 , thus confirming the convergent validity. For discriminant validity MSV should be < AVE and ASV < AVE. As evident from Table 2, all the values are within the acceptable ranges, thus also confirming the discriminant validity of the constructs (Tarhini, Teo, and Tarhini, 2016; Fornell and Larcker, 1981).

Table 2. Reliability, Convergent Validity and Discriminant Validity

\begin{tabular}{lllllll}
\hline & $\begin{array}{l}\text { No. } \\
\text { of } \\
\text { Items }\end{array}$ & AVE & $\begin{array}{l}\text { Composite } \\
\text { Reliability } \\
(\mathrm{CR})\end{array}$ & $\begin{array}{l}\text { Cronbach's } \\
\text { Alpha } \\
(\alpha)\end{array}$ & MSV & ASV \\
\hline $\begin{array}{l}\text { Business performance } \\
\begin{array}{l}\text { Supply risk management } \\
\text { performance }\end{array}\end{array}$ & 6 & 0.537 & 0.873 & 0.844 & 0.389 & 0.201 \\
$\begin{array}{l}\text { Manufacturing risk } \\
\text { management performance }\end{array}$ & 5 & 0.583 & 0.801 & 0.833 & 0.501 & 0.347 \\
$\begin{array}{l}\text { Supplier orientation } \\
\text { Supplier dependency }\end{array}$ & 5 & 0.515 & 0.841 & 0.855 & 0.508 & 0.388 \\
Production flexibility & 3 & 0.529 & 0.771 & 0.829 & 0.352 & 0.213 \\
& 3 & 0.555 & 0.713 & 0.822 & 0.174 & 0.089
\end{tabular}




\begin{tabular}{lllllll}
$\begin{array}{l}\text { Maturity of manufacturing } \\
\text { process }\end{array}$ & 2 & 0.554 & 0.723 & 0.757 & 0.515 & 0.265 \\
HR management & 3 & 0.544 & 0.781 & 0.871 & 0.396 & 0.225 \\
Customer orientation & 3 & 0.592 & 0.813 & 0.897 & 0.540 & 0.315 \\
Maturity of SCRM process & 4 & 0.649 & 0.880 & 0.932 & 0.577 & 0.34 \\
Culture & 3 & 0.545 & 0.705 & 0.765 & 0.540 & 0.365 \\
\hline
\end{tabular}

AVE > .50; CR>.70; Cronbach's Alpha >.70; MSV < AVE; and ASV < AVE.

The exploratory factor analysis (EFA) of the survey results indicated that all item factor loading values were greater than 0.6 with a sample size of 103 , which can be considered as significant (Field, 2013). There are four major indicators that can be used to test the construct validity in EFA: the accumulative total of variance, factor loading, KaiserMeyer-Olkin (KMO) value and Bartlett's test. According to Field (2013), the accumulative total reflects the degree of effective explanation of common factors for scales. Lastly, KMO value and Bartlett test are used to indicate the extent of the integrated concept of the whole variables or scales. Table 3 presents the result of factors analysis for variables described in the paper. Apart from systemic purchasing (single item, hence excluded in the analysis) and maturity of manufacturing process (not suitable for KMO test with two subitems), the KMO values of other 10 variables are all above 0.6 , and the Bartlett's test of Sphericity is significant $(\mathrm{p}<0.01)$. The results indicate that the validity of variables used in this research is acceptable.

Table 3. Kaiser-Meyer-Olkin (KMO)

\begin{tabular}{llll}
\hline Variables & KMO & $\begin{array}{l}\text { Chi- } \\
\text { Square }\end{array}$ & Df \\
\hline Business performance & 0.771 & 307.336 & 15 \\
Supply risk management performance & 0.837 & 216.039 & 15 \\
Manufacturing risk management performance & 0.819 & 146.651 & 10 \\
Supplier orientation & 0.784 & 250.020 & 10 \\
Supplier dependency & 0.721 & 112.924 & 3 \\
Flexibility & 0.719 & 108.317 & 3 \\
Maturity of manufacturing process & 0.500 & 47.575 & 1 \\
HR management & 0.689 & 165.058 & 3 \\
Customer orientation & 0.715 & 200.889 & 3 \\
Maturity of SCRM process & 0.848 & 345.514 & 6 \\
Culture & 0.619 & 99.867 & 3 \\
\hline
\end{tabular}




\section{Findings}

The survey questionnaire resulted in 103 valid responses. Initially, respondents were asked about the business performance, the supply risk management performance and manufacturing risk management performance and asked to rank the items using a five point Likert scale. The responses achieved 3.67 and 3.70 average means, with supplier dependency and systemic purchasing relatively low with 3.26 and 3.31, indicating that in general the constructs (business performance, the supply risk management performance and manufacturing risk management performance) were relevant to supply chain practices and can/or are partially applied to the surveyed organizations in general (See Table 4).

Table 4: Mean value of variables

\begin{tabular}{llllll}
\hline Research variables & $\mathrm{N}$ & Min & Max & Mean & SD \\
\hline Business performance & 103 & 1.50 & 5.00 & 3.73 & 0.80 \\
Supply risk management performance & 103 & 1.00 & 5.00 & 3.67 & 0.72 \\
Manufacturing risk management performance & 103 & 1.00 & 5.00 & 3.70 & 0.76 \\
Supplier orientation & 103 & 1.20 & 5.00 & 3.68 & 0.89 \\
Supplier dependency & 103 & 1.00 & 5.00 & 3.26 & 1.14 \\
Systemic purchasing & 103 & 1.00 & 5.00 & 3.31 & 1.16 \\
Flexibility & 103 & 1.00 & 5.00 & 3.80 & 0.91 \\
Maturity of manufacturing process & 103 & 1.00 & 5.00 & 3.52 & 1.13 \\
HR management & 103 & 1.00 & 5.00 & 3.79 & 0.98 \\
Customer orientation & 103 & 1.33 & 5.00 & 3.83 & 0.89 \\
Maturity of SCRM process & 103 & 1.00 & 5.00 & 3.46 & 1.06 \\
Culture & 103 & 1.00 & 5.00 & 3.72 & 0.89 \\
\hline
\end{tabular}

The correlation analysis has been divided into three parts following the conceptual model. Part one (see Table 5) investigated the correlation between the major constructs of business performance, supply risk management performance and manufacturing risk management performance. Part two investigated the correlation between supply risk management performance and the other aforementioned factors influencing it (see Table 6). Part three investigated the correlation between manufacturing risk management performance and the aforementioned factors influencing it (see Table 7). The correlation coefficient between business performance and supply risk management performance was found to be 0.569 , whereas correlation between business performance and manufacturing risk management performance was found to be 0.624 . Both correlation coefficients are significant at a $\mathrm{P}<0.01$ level. Therefore, it can be concluded that business performance has a substantial and close correlation with supply risk management performance and manufacturing risk 
management performance respectively. Additionally, the correlation between supply risk management performance and manufacturing risk management performance is noteworthy. The correlation coefficient value was found to be 0.706 significant at $\mathrm{P}<0.01$ level, reflecting that the two variables have a high positive correlation.

Table 5. Correlation analysis - Part one

\begin{tabular}{lllll}
\hline & $\begin{array}{l}\text { Business } \\
\text { performance }\end{array}$ & $\begin{array}{l}\text { Supply } \\
\text { management } \\
\text { performance }\end{array}$ & $\begin{array}{l}\text { risk } \\
\text { Manufacturing } \\
\text { performance }\end{array}$ & risk \\
\hline $\begin{array}{l}\text { Business performance } \\
\begin{array}{l}\text { Supply risk management } \\
\text { performance }\end{array}\end{array}$ & 1 & & & \\
$\begin{array}{l}\text { Manufacturing risk } \\
\text { management } \\
\text { performance }\end{array}$ & $.569^{* *}$ & 1 & 1 & \\
\hline$* *$ Correlation is significant at the 0.01 level (2-tailed). & &
\end{tabular}

As shown in Table 6, apart from the variable of firm size, supply risk management performance has significant and positive correlation with the other six variables. Surprisingly, the correlation between supply risk management performance and supplier dependency is positive. As expected, supplier dependency is considered as a factor increasing supply risk (Hallikas and Lintukangas, 2016). However, this may be because companies heavily dependent on suppliers are conscious of the related supply risk but they feel they have in place an effective process of supply risk management to counteract it. Turning to firm size, the correlation coefficient is close to zero, and it is not significant. Therefore, there is no association between supply risk management performance and firm size.

Table 6. Correlation analysis Part two

\begin{tabular}{lllllllll}
\hline Variables & 1 & 2 & 3 & 4 & 5 & 6 & 7 & 8 \\
\hline Supply risk management performance & 1 & & & & & & & \\
Supplier orientation & $.722^{* *}$ & 1 & & & & & \\
Supplier dependency & $.463^{* *}$ & $.539^{* *}$ & 1 & & & & \\
Systemic purchasing & $.306^{* *}$ & $.299^{* *}$ & $.418^{* *}$ & 1 & & & \\
Customer orientation & $.660^{* *}$ & $.760^{* *}$ & $.469^{* *}$ & $.263^{* *}$ & 1 & & \\
Maturity of SCRM process & $.663^{* *}$ & $.734^{* *}$ & $.594^{* *}$ & $.370^{* *}$ & $.704^{* *}$ & 1 & & \\
Firm size & .021 & -.072 & $.231^{* *}$ & .144 & -.065 & .166 & 1 \\
Culture & $.531^{* *}$ & $.605^{* *}$ & $.391^{* *}$ & $.199^{* *}$ & $.529^{* *}$ & $.590^{* *}$ & .087 & 1 \\
\hline$*$ * Correlation is significant at the 0.01 level (2-tailed). & & & & & & \\
*. Correlation is significant at the 0.05 level (2-tailed). & & & & & &
\end{tabular}


As shown in Table 7, the association between manufacturing risk management performance and firm size is not significant, which indicate there is no correlation between the two variables. Apart from firm size, the other six variables have prominent and positive correlations with manufacturing risk management performance.

Table 7. Correlation analysis Part three

\begin{tabular}{lllllllll}
\hline Variables & 1 & 2 & 3 & 4 & 5 & 6 & 7 & 8 \\
\hline $\begin{array}{l}\text { Manufacturing risk management } \\
\text { performance }\end{array}$ & 1 & & & & & & & \\
Flexibility & $.497^{* *}$ & 1 & & & & & \\
Maturity of manufacturing & $.396^{* *}$ & $.354^{* *}$ & 1 & & & & & \\
process & $.515^{* *}$ & $.419^{* *}$ & $.594^{* *}$ & 1 & & & & \\
HRM & $.568^{* *}$ & $.640^{* *}$ & $.463^{* *}$ & $.685^{* *}$ & 1 & & & \\
Customer orientation & $.517^{* *}$ & $.564^{* *}$ & $.630^{* *}$ & $.735^{* *}$ & $.704^{* *}$ & 1 & & \\
Maturity of SCRM process & .015 & $-.236^{*}$ & $.345^{* *}$ & .149 & -.065 & .166 & 1 & \\
Firm size & $.449^{* *}$ & $.516^{* *}$ & $.518^{* *}$ & $.617^{* *}$ & $.529^{* *}$ & $.590^{* *}$ & .087 & 1 \\
Culture & * Correlation is significant at the 0.01 level (2-tailed). & & & & & & \\
\hline *. Correlation is significant at the 0.05 level (2-tailed). & & & & & & & \\
\end{tabular}

In the linear regression analysis, supply risk management performance is analyzed as a dependent variable, while culture, firm size, systemic purchasing, supplier dependency, customer orientation, maturity of SCRM processes, supplier orientation are analyzed as independent variables. The regression coefficient of supplier orientation was 0.312 , significant at $\mathrm{P}<0.01$, indicating supplier orientation has a positive and significant influencing relationship with supply risk management performance. Similarly, the regression coefficient of customer orientation was 0.149 significant at $\mathrm{P}<0.01$. The results also reflect a positive and respectably significant influencing relationship between customer orientation and supply risk management performance. The regression coefficients of the other five variables were not significant. Hence, they have no influencing relationship with supply risk management performance. Secondly, manufacturing risk management is regarded as a dependent variable in the model and the seven independent variables are flexibility, maturity of manufacturing processes, HRM, customer orientation, the maturity of SCRM process, firm size, and culture. The coefficients indicate that flexibility has a positive and significant influence on the performance of manufacturing risk management, with a regression coefficient of 0.175 significant at $\mathrm{P}<0.1$. Similarly, the results reveal that customer orientation is significantly and positively influencing the result of manufacturing risk management (coefficient 
0.206). However, the results of the other five independent variables indicate that they have no significant influence on the performance of manufacturing risk.

The findings predicted that supply risk management influences business performance $(\mathrm{H} 1)$, as the result of supply risk management has significant and positive impact on organization's business performance. In turn, it demonstrates the importance of supply risk management for Chinese manufacturers. The interview findings also supported this finding as all six respondents in the interviews strongly agreed on hypothesis (H1). Similarly, manufacturing risk management influences business performance $(\mathrm{H} 2)$, as the Chinese companies indicated that those who manage manufacturing risk well are likely to perform better than competitors with respect to efficiency and effectiveness. In general, interviewees agreed that the risks in manufacturing could result in direct and significant losses to the corporations. As one of the respondents stated, "We just suffered from a serious quality issue in last year that caused us huge financial and reputation loss." In turn, it reveals the significance of manufacturing risk management performance to Chinese manufacturers. Another interesting finding is that supplier orientation influences supply risk management performance (H3). This indicates that from the perspective of a buyer company, the orientation towards suppliers enhances its capability to manage risks coming from the supply side. All interviewees agreed that supplier orientation is essential for them to manage supply risks. As one of the respondents mentioned, "The activity of supplier orientation is just like bringing the suppliers into our management system, which is useful for reducing supply risks." Moreover, one SCM expert emphasized that supplier orientation can facilitate the development of supplier, and the improvement of suppliers will result in reducing supply risks.

Another positive assertion was that customer orientation influences both supply risk and manufacturing risk management performance (H6a, H6b). It indicates that concentrating on customer requirements can contribute to the reduction of risks in both supply and manufacturing stages of the supply chain. One of the interviewees asserted that customer orientation is a major challenge faced by most enterprises as it affects a range of supply chain risks. Similarly, another respondent said, "customer orientation not only has positive impacts on reducing supply chain risks, but also helps to improve our management." This is reinforced by the fact that the study indicates that production flexibility influences the performance of manufacturing risk management (H8). Within the Chinese manufacturing companies, the reacting and adjusting capabilities of production increase the firm's ability 
in reducing manufacturing risks. The interview findings also showed that production flexibility is more significant to organizations with unstable demands than to firms with stable needs. One of the respondents from an auto enterprise said, "Flexibility is quite important for us. As our sales decline dramatically recently, we are able to put four different cars in the same production line, so that the production cost can be maintained at a reasonable level."

On the other hand, despite the supplier dependency is extensively regarded as a threat to business, it does not have influences on the performance of supply risk management (H4). The interview findings also did not support this notion and most interviewees indicated that they do not have concerns about supplier dependency since there are adequate alternative resources in the market, in line with Hallikas and Lintukangas (2016). However, the systemic purchasing activities such as centralized purchasing indicated no impact upon the performance of managing supply risk in Chinese manufacturing companies (H5) in contrast to the findings of Hallikas and Lintukangas (2016). However, this hypothesis was partially supported in the interview findings. One of the supplier quality engineer argued that systemic purchasing is meaningful for reducing quality risks from supply side, and improving suppliers' service level. Another interviewee stressed that systemic purchasing is significant for organizations to simplify its categorization of buying items, therefore, inventory risks and other risks arise from complicated product mix can be reduced. Hypotheses $7 \mathrm{a}, 7 \mathrm{~b}$ were not supported indicating that the maturity of SCRM process does not influence the performance of both supply and manufacturing risk management. The survey findings show that maturity of production has no impact on manufacturing risk management performance in the Chinese manufacturing companies (H9), notwithstanding the fact that the maturity level of manufacturing processes is often regarded as an essential factor for reducing risks of quality, disruption and dependency on labor. However, unlike survey findings, the interview results are consistent with the literature (Harrison, 2014; Isoherranen, 2015). Most respondents recognized the significance of process maturity in managing manufacturing risks. One of the respondents mentioned, "We are threatened by serious quality issues due to the lack of mature manufacturing processes."

The role of HR management is recognized in the literature as closely linked to the performance of manufacturing risk management; however, both the survey and interview findings indicated that the capability of HR management has no impact on manufacturing risk management performance $(\mathrm{H} 10)$. Another expected finding was a positive impact 
between culture and supply and manufacturing risk performance since the Chinese culture is widely regarded as a critical factor affecting business relationships. However, the study indicated that there is no significant impact on the performance of supply and manufacturing risk management (H12a, H12b). Likewise, the interview findings present a similar view. All respondents denoted that Chinese culture characteristics (i.e. guanxi) have no significant impacts on supply and manufacturing risk management performances. Neither firm size seemed to influence the performance of supply and manufacturing risk management (H11a, H11b).

\section{Discussions}

In the Chinese context, the correlation between business performance and manufacturing risk management performance was higher than the one between business performance and supply risk management performance. To better understand this result, the research also investigated the factors influencing the performance of both supply and manufacturing risk management.

\section{Factors affecting supply risk management performance}

The literature review indicated three factors affecting the performance of supply risk management, i.e. supplier orientation, supplier dependency, and systemic purchasing. According to Hallikas and Lintukangas (2016), supplier orientation involves supplierdevelopment activities that can positively influence the performance of supply risk management. Similarly, Giunipero and Eltantawy (2004) noted that supplier-development activities could assist in reducing the uncertainties and supply chain risks. This is important as "the identification and management of risks for the supply chain, through a co-ordinated approach amongst supply chain members, to reduce supply chain vulnerability as a whole" (Jüttner et al., 2003, p. 201). Thun and Hoenig (2011: 246) also note that the complexity of supply chains can be managed through "certified suppliers in order to guarantee high quality and a high on-time delivery ratio." Hallikas and Lintukangas (2016) claimed that supplier-development activities could effectively and efficiently reduce the risks coming from the supply side of the supply chain. This argument is supported by survey results. In fact, the regression analysis confirms the significant and positive influence of supplier orientation on the performance of supply risk management, a view that was also supported by interviewees. 
Moreover, in the case of outsourcing, supplier dependency will result in a higher risk of losing internal resources and capabilities, which are critical for the competitiveness of the buying firm. However, the study findings do not support this point of view in the Chinese manufacturing context. The limited concerns regarding supplier dependency may be due to the presence of adequate alternative resources in the Chinese market. Hallikas and Lintukangas (2016) illustrated the concept of supplier dependency from the perspective of transaction costs. They pointed out that a high reliance on suppliers can result in higher transaction costs. The high reliance also may correlate to the increased number of global customers outsourcing their products to China (Lin and Zhou, 2011). Therefore, it can be concluded that supplier dependency does not affect the performance of supply risk management in Chinese manufacturing context.

Finally, according to Hallikas and Lintukangas (2016) and Giunipero and Eltantawy (2004) systemic purchasing can have a direct impact on supply risk management performance. Through systemic purchasing companies reduce the number of suppliers and thus improve their ability to control quality and manage their supplier base. Our findings acknowledged the role of purchasing but indicated no correlation between supply risk performance and systemic purchasing. In addition, systemic purchasing concentrated the buying volume on certain suppliers, which enable organizations to negotiate for better service level with suppliers. However, the survey results denote that systemic purchasing has no impact on supply risk management performance. Further research needs to be conducted to understand whether systematic purchasing has become less important as the Chinese manufacturing supply chains possess a more co-ordinated approach amongst supply chain members (Jüttner et al., 2003) or whether the findings can be an indicator to manufacturing companies resources and resource dependency (Thun and Hoenig, 2011).

\section{Factors affecting manufacturing risk management performance}

According to Lamarre et al. (2009), production flexibility is essential for manufacturers in the current turbulent and unpredictable market environment. The capabilities to adjust production volume, product mix, and lead-time enable manufacturers to reduce manufacturing risks, such as loss of market share, high inventory, and high production cost. This view is confirmed by the survey results as well as interviews, which indicate a positive influencing relationship between production flexibility and manufacturing risk 
management performance. In the context of Chinese manufacturers, production flexibility is in fact recognised as a major challenge since their products are customized, hence the importance of being able to quickly adjust production when demand changes. Literature suggests that the impact of production flexibility is dependent on sectors (Lamarre et al., 2009) and consequently this opens further avenues for future research to highlight the role and impact of production flexibility on risk management in specific sectors.

Isoherranen et al. (2015) stated that the mature manufacturing processes can positively improve firms' operational performance, including managing manufacturing risks. Nevertheless, the survey findings did not support this argument. Although the correlation analysis showed there is an association between the maturity of manufacturing processes and manufacturing risk management performance, the regression analysis indicated there is no influencing relationship between them.

Finally, according to Mangan and Christopher (2005) HR management has a crucial impact on business performance, including the performance of manufacturing risk management process. For example, the capability of HR management has an influence on reducing risks such as strike, safety issues, and dependencies on specific employees. However, the survey results indicated that there is no influencing relationship between HR management and manufacturing risk management performance. Hence, it would be opportune to further explore this relationship to complement the results of our investigation in other geographical contexts.

\section{Factors affecting the performance of both supply and manufacturing risk management}

The literature review indicated four factors that influence the performance of SCRM, namely customer orientation, firm size, the maturity of SCRM process and culture. Consequently, it was assumed that these factors affect the performance of both supply and manufacturing risk management.

As argued by Hallikas and Lintukangas (2016), customer value orientation is critical for firms as it allows them to react to demand changes rapidly and in a proactive manner. As a result, customer satisfaction can be promoted and thus, risks connected to customer needs can be reduced. This argument receives supports from survey results. In fact, they reveal a significant and positive influencing relationship between customer orientation and both supply and manufacturing risk management. 
Firm size is regarded as a factor influencing organisations' SCRM performance since large companies are found to be performing better in managing information and utilizing knowledge for risk management purposes (Hallikas and Lintukangas, 2016). However, results from survey did not confirm this argument. The findings indicated that there are no associations between firm size and supply risk and manufacturing risk management performance.

As raised by Hoffmann et al. (2013), the maturity of SCRM process is strictly connected with its performance. Surprisingly, this relationship is not supported by the survey findings. The regression analysis result indicated that there is no influence relationship between the maturity of SCRM processes and supply risk and manufacturing risk management performance. This may be also in line with Cheng et al.'s (2012) research whereby the supply chain risk woven within the supply chain risk practices as it has been seen as an integrative element within the Chinese organisations supply chain.

Company culture is widely recognized in the literature to have influences on businesses (Jia and Zsidisin, 2014; Cheng et al., 2012). Chinese culture characteristics such as guanxi can be utilized to promote the effectiveness of communication and trust in supply chain relationships, which will result in a reduction of related supply chain risks and better performance of SCRM process (Cheng et al., 2012). Even if survey results identified a correlation between culture and risk performance, the regression analysis revealed there is no relationship between these elements.

\section{Conclusions, implications, limitations, and future research}

The result of the study reveal both types of risks management are essential to Chinese manufacturing firms, as they are playing vital roles in those organizations' business performance. In particular, the findings of the study indicated that supply orientation was found to be effective in managing supply risk, while supply dependency indicated no significant influence on it, thus leading to rethink Chinese manufacturer's strategy accordingly. However, the customer orientation was found to have positive effects on manufacturing and supply risk.

Another interesting finding was that not all the relationships identified in the literature were confirmed. Therefore, the study included interesting findings contradictory to previous research, such as that there is no relationship between the maturity of SCRM processes and 
supply risk and manufacturing risk management performance. Hence, the contextual setting and manufacturing sector may be different within country and industry settings (Lin and Zhou, 2011).

The study provides important theoretical and practical contributions. Firstly, our findings contributes to the existing body of knowledge by providing empirical evidence on the relationships between supply risk, manufacturing risk and business performance in Chinese context as well as through utilizing the institutional theory lens added to the limited body of empirical knowledge in the area. Our study further challenges the existing notion that supplier dependency affects the supply risk management process, as this relationship is context dependent, as we did not find any evidence of this in the Chinese context. Moreover, this study used a combination of quantitative and qualitative methods, which is often limited in this area. Findings of the study are also of great importance for manufacturing organisations operating in China or seeking to operate in the region. Manufacturing companies can greatly benefit from the understanding of the dynamics between the various factors that can influence their business performance particularly the supply and manufacturing risk management. Although the findings are applicable across all manufacturing firms, the sampling from Chinese context limits its generalisability beyond China. Therefore, future research should focus on data collection beyond the Chinese manufacturing context and perhaps expand the study regionally or if possible on a global scale. Future studies should target larger survey responses that could be complemented with further interviews with practitioners/experts. Future investigation could also focus beyond manufacturing and supply risks, and explore other risks (e.g. demand risk, infrastructure risk) that also have considerable impact on the industry.

This work is one of the few efforts to investigate supply or manufacturing risk in supply chain practices in China, therefore our investigation and the findings of the study are relatively exploratory in nature. We believe a longitudinal investigation based on the findings of this work can help to identify patterns of long-term manufacturing and supply chain risk and how they are managed, and whether this performance has an impact upon the economic direction of society over the next few decades. In addition, we believe that future research should try to tease out various variations between regions, to see the level of manufacturing and supply risk observed.

\section{References}


Aberdeen Group, (2013). Operational Risk Management: How Best-in-Class Manufacturers Improve Operating Performance with Proactive Risk Reduction. Analyst Insight.

[online]

pp.111,https://www.plantservices.com/assets/wp_downloads/pdf/operational-riskmanagement-improve-operating-performance.pdf [Accessed 18 Aug. 2016].

Adebanjo, D., Teh, P. and Ahmed, P. K. (2017). The impact of supply chain relationships and integration on innovative capabilities and manufacturing performance: the perspective of rapidly developing countries. International Journal of Production Research, DOI: 10.1080/00207543.2017.1366083

Alcantara, P. (2014). An international survey to consider the origin, causes \& consequences of supply chain disruption. Supply Chain Resilience. http://www.thebci.org/index.php/ businesscontinuity/cat_view/24-supply-chaincontinuity/33-supply-chain-continuity/140-

bciresources?limit $=5 \&$ limitstart $=0$ \&order $=$ name\&dir=DESC [Accessed 18 Aug. 2016].

Athukorala, P. C. (2011). Asian Trade Flows: Trends, Patterns and Projections. ADB Economics Working Paper Series, Asian Development Bank, 241, January 2011

Baghalian, A., Rezapour, S. and Farahani, R. (2013). Robust supply chain network design with service level against disruptions and demand uncertainties: A real-life case. European Journal of Operational Research, 227(1), pp.199-215.

Bak, O. (2018). Supply chain risk management research agenda: From a literature review to a call for future research directions. Business Process Management Journal, 24(2), pp. 567-588.

Berg, E., Knudsen, D. and Norrman, A. (2008). Assessing performance of supply chain risk management programmes: a tentative approach. IJRAM, 9(3), pp.288.

Bi, K., Huang, P. and Ye, H. (2015). Risk identification, evaluation and response of lowcarbon technological innovation under the global value chain: A case of the Chinese manufacturing industry. Technological Forecasting and Social Change, 100, pp.238248.

Bronzo, M., de Resende, P. T. V., de Oliveira, M. P. V., McCormack, K. P., de Sousa, P. R., \& Ferreira, R. L. (2013). Improving performance aligning business analytics with process orientation. International Journal of information management, 33(2), pp. 300307.

Bustinza, O., Arias-Aranda, D. and Gutierrez-Gutierrez, L. (2010). Outsourcing, competitive capabilities and performance: an empirical study in service firms. International Journal of Production Economics, 126(2), pp.276-288.

Chen, T., Leung, K., Li, F. and Ou, Z., (2015). Interpersonal harmony and creativity in China. Journal of Organizational Behavior, 36 (5), pp.648-672.

Cheng, T., Yip, F. and Yeung, A. (2012). Supply risk management via guanxi in the Chinese business context: The buyer's perspective. International Journal of Production Economics, 139(1), pp.3-13.

Christopher, M. and Peck, H. (2004). Building the Resilient Supply Chain. Int Jrnl Logistics Management, 15(2), pp.1-14.

Datta, P. P., \& Christopher, M. G. (2011). Information sharing and coordination mechanisms for managing uncertainty in supply chains: a simulation study. International Journal of Production Research, 49(3), pp. 765-803.

Cigolini, R. and Rossi, T. (2010). Managing operational risks along the oil supply chain. Production Planning \& Control, 21(5), pp.452-467.

CIPS, (2013). Risk Management in Purchasing and Supply Management. Key procurement topic. [online] CIPS. https://www.cips.org/Documents/Knowledge/Procurement- 
Topics-and-Skills/3-Risk-Mitigation/Risk-AnalysisandManagement/Risk_Management_in__Purchasing_and_Supply_Management.pdf [Accessed 18 Aug. 2016].

Colicchia, C. and Strozzi, F. (2012). Supply chain risk management: a new methodology for a systematic literature review. Supply Chain Management: An International Journal, 17 (4), pp. $403-418$.

Conrad, L. and Walker, P. (2012). Strategic risk: do not forget your supply chain!. [online] Zurich Insurance Company Ltd. https://www.zurich.com/_/media/dbe/corporate/docs /whitepapers/strategic-risk-do-not-forget-your-supply-chain-2014.pdf [Accessed 18 Aug. 2016].

Das, K. And Lashkari, R.S. (2015). Risk readiness and resiliency planning for a supply chain. International Journal of Production Research, 53(22), pp. 6752-6771.

Dillman, D., Smyth, J., Christian, L. and Dillman, D. (2009). Internet, mail, and mixedmode surveys. Hoboken, N.J.: Wiley \& Sons.

DiMaggio, P.J and Powell,W.W.(1983).The iron cage revisited:institutional isomorphism and collective rationality in organizational fields, American Sociological Review 48 (2) pp. 147-160.

Ellinger, A., Chen, H., Tian, Y. and Armstrong, C. (2015). Learning orientation, integration, and supply chain risk management in Chinese manufacturing firms. International Journal of Logistics Research and Applications, 18(6), pp.476-493.

Eloot, K., Huang, A. and Lehnich, M. (2013). A new era for manufacturing in China. McKinsey Quarterly. [online] McKinsey \& Company. Available at: http://www.mckinsey.com/business-functions/operations/our-insights/a-new-era-formanufacturing-in-china [Accessed 18 Aug. 2016].

Epp, A.M., Price, L.L., 2011. Designing solutions around customer network identity goals. J. Mark. 75 (2), 36-54.

Farh, J.L., Zhong, C.B. and Organ, D.W. (2004). Organizational citizenship behavior in the People's Republic of China. Organization Science, 15 (2), pp. 241-253.

Fenwick, D., Daim, T., Iskin, I. and Dahlawi, Y. (2010). Exploring the influence of cultural elements on Chinese manufacturing quality. Journal of Technology Management in China, 5(2), pp.141-157.

Field, A. (2013). Discovering Statistics using IBM SPSS Statistics. 4th ed. London: SAGE Publications.

Freise, M. and Seuring, S. (2015). Social and environmental risk management in supply chains: a survey in the clothing industry. Logist. Res., 8(2), pp. 1-12.

Fornell, C., \& Larcker, D. F. (1981). Structural equation models with unobservable variables and measurement error. Journal of marketing research, 18 (1), pp. 39-50.

Goh, M., Lim, J. and Meng, F. (2007). A stochastic model for risk management in global supply chain networks. European Journal of Operational Research, 182(1), pp.164173.

Giunipero, L.C. and Eltantawy, R.A. (2004). Securing the upstream supply chain: a risk management approach. International Journal of Physical Distribution \& Logistics Management, 34(9), pp. 698-713

Hallikas, J. and Lintukangas, K. (2016). Purchasing and supply: An investigation of risk management performance. International Journal of Production Economics, 171, pp.487-494.

Harrison, C. (2014). A review of automation in manufacturing illustrated by a case study on mixed-mode hot forging. Manufacturing Review, 1, pp.1-15.

Hillberry, R., \& Zhang, X. (2018). Policy and performance in customs: evaluating the trade facilitation agreement. Review of International Economics, 26(2), pp. 438-480. 
Ho, W., Zheng, T., Yildiz, H. and Talluri, S. (2015). Supply chain risk management: a literature review. International Journal of Production Research, 53(16), pp.5031-5069.

Hoffmann, P., Schiele, H. and Krabbendam, K. (2013). Uncertainty, supply risk management and their impact on performance. Journal of Purchasing and Supply Management, 19(3), pp.199-211.

Hong, S., Kwon, I. and Li, J. (2014). Assessing the Perception of Supply Chain Risk and Partnerships Using Importance-Performance Analysis Model: A Case Study of SMEs in China and Korea. Supply Chain Forum, 15(2), pp.110-125.

Huang, G., Zhang, A. and Liu, X. (2013). A supply chain configuration model for reassessing global manufacturing in China. Journal of Manufacturing Technology Management, 24(5), pp.669-687.

Indrawati, C., Karningsih, P., Vanany, I. and Gurning, R. (2014). Development of Supply Chain Risks Interrelationships Model Using Interpretive Structural Modeling and Analytical Network Process. Journal of Proceeding Series, 1, pp.449-453.

Isoherranen, V., Karkkainen, M. and Kess, P. (2015). Operational excellence driven by process maturity reviews: A case study of the ABB corporation. In: Industrial Engineering and Engineering Management (IEEM), 2015 IEEE International Conference on. Singapore: IEEE, pp.1372 - 1376.

Jia, F. and Rutherford, C. (2010). Mitigation of supply chain relational risk caused by cultural differences between China and the West. Int Jrnl Logistics Management, 21(2), pp.251-270.

Jia, F. and Zsidisin, G. (2014). Supply Relational Risk: What Role Does Guanxi Play?. J Bus Logist, 35(3), pp.259-267.

Jordan, C. \& Bak, O. (2016). The growing scale and scope of the supply chain: a reflection on supply chain graduate skills. Supply Chain Management: An International Journal, 21(5), 610-626.Juttner, U., Peck, H. and Christopher, M. (2003). Supply chain risk management: outlining an agenda for future research. International Journal of Logistics Research and Applications, 6(4), pp.197-210.

Kamann, Dirk-Jan F., Wout D., and Sander de L. (2016). Preparing for new competitive challenges. Special issue on the 24th annual IPSERA conference.Journal of Purchasing and Supply,22, pp. 155-159.

Ke, B., Lennox, C. S., \& Xin, Q. (2014). The effect of China's weak institutional environment on the quality of Big 4 audits. The Accounting Review, 90(4), pp. 15911619.

Kumar, R. (2011). Research methodology. 3rd ed. London: SAGE.

Kumar, S. and Sosnoski, M. (2009). The Effects of China's Economic Growth on Domestic and International Supply Chains: Assessing the Risks. Supply Chain Forum, 9(2).

Lamarre, E., Pergler, M. and Vainberg, G. (2009). Reducing risk in your manufacturing footprint. The McKinsey Quarterly. [online] McKinsey \& Company. Available at: http://www.mckinsey.com/business-functions/strategy-and-corporate-finance/ourinsights/reducing-risk-in-your-manufacturing-footprint [Accessed 18 Aug. 2016].

Li, G., Fan, H., Lee, P. and Cheng, T. (2015). Joint supply chain risk management: An agency and collaboration perspective. International Journal of Production Economics, 164, pp.83-94.

Lin, Y. and Zhou, L. (2011). The impacts of product design changes on supply chain risk: a case study. International Journal of Physical Distribution \& Logistics Management, 41(2), pp.162-186.

Liu, L., Ji, J., Yu, H., Hu, J. and Fan, T. (2007). Supply chain risk management in Chinese process industries. In: 2007 International Conference on Wireless Communications, Networking and Mobile Computing. Shanghai: IEEE, pp.4923 - 4926. 
Ma, L. and Tsui, A.S. (2015). Traditional Chinese philosophies and contemporary leadership, The Leadership Quarterly, 26 (1) pp. 13-24.

Mangan, J., Lalwani, C. and Gardner, B. (2004), "Combining quantitative and qualitative methodologies in logistics research," International Journal of Physical Distribution \& Logistics Management, 34 (7), pp. 565-578.

Mangan, J. and Christopher, M. (2005) "Management development and the supply chain manager of the future", The International Journal of Logistics Management, Vol. 16 Issue: 2, pp.178-191, https://doi.org/10.1108/09574090510634494

Manyika, J., Sinclair, J., Dobbs, R., Strube, G., Rassey, L., Mischke, J., Remes, J., Roxburgh, C., George, K., O'Halloran, D. and Ramaswamy, S. (2012). Manufacturing the future: The next era of global growth and innovation. [online] McKinsey Global Institute. Available at: http://www.mckinsey.com/business-functions/operations/ourinsights/the-future-of-manufacturing [Accessed 18 Aug. 2016].

Marchese, K. and Paramasivam, S. (2013). The Ripple Effect How manufacturing and retail executives view the growing challenge of supply chain risk. [online] Deloitte Development LLC. Available at: http://www2.deloitte.com/content/dam/Deloitte/ global/Documents/Process-and-Operations/gx-operations-consulting-the-rippleeffect-041213.pdf [Accessed 18 Aug. 2016].

Nagy, J. and Venter, L. (2011). How risk management in supply chains affects supply chain performance? PhD. Corvinus University of Budapest.

Oliver, C. (1991). Strategic responses to institutional processes. Academy of Management Review, 16, pp. 145-179.

Olson, D.L. (2014). Supply chain risk management. 2nd ed. New York: Business Expert Press, LLC.

Olson, D.L. and Wu, D. D. (2010). A review of enterprise risk management in supply chain. Kybernetes, 39(5), pp.694-706.

Olson, D.L. and Wu, D. D. (2011). Risk management models for supply chain: a scenario analysis of outsourcing to China. Supply Chain Management: An International Journal, 16(6), pp.401-408.

Pallant, J. (2010). PASW and SPSS survival manual. Maidenhead: Open University Press.

PwC, (2015). PwC and the MIT Forum for Supply Chain Innovation-Making the right risk decisions to strengthen operations performance. [online] PricewaterhouseCoopers International Limited. Available at: http://www.pwc.com/gx/en/services/advisory/consulting/operations/supply-chainmanagement/supply-chain-risk-management.html [Accessed 18 Aug. 2016].

Qiang, P. and Nagurney, A. (2012). A bi-criteria indicator to assess supply chain network performance for critical needs under capacity and demand disruptions. Transportation Research Part A: Policy and Practice, 46(5), pp.801-812.

Qiang, Q., Huang, Z., Ke, K., \& Yang, Y. X. (2014). Overview of supply chain risk management and the current issues of closed-loop supply chain in China. International Journal of Business Continuity and Risk Management, 5(3), pp. 236-243.

Rajagopal, V, Venkatesana, S. P. And Goh, M. (2017). Decision-making models for supply chain risk mitigation: A review. Computers \& Industrial Engineering, 113, pp. 646682.

Reiner, G. (2005). Customer-oriented improvement and evaluation of supply chain processes supported by simulation models. International Journal of Production Economics, 96(3), pp. 381-395.

Repenning, N. P., \& Sterman, J. D. (2001). Nobody ever gets credit for fixing problems that never happened: creating and sustaining process improvement. California management review, 43(4), 64-88. 
Ruane, J. (2005). Essentials of research methods. Malden, MA: Blackwell Pub.

Saunders, M., Lewis, P. and Thornhill, A. (2016). Research methods for business students. 5th ed. London: Prentice Hall.

Sharma, S. and Bhat, A. (2014). Supply Chain Risk Assessment Tools and Techniques in the Automobile Industry: A Survey. The IUP Journal of Supply Chain Management, 6(1), pp.67-76.

Strauss, A., and Corbin, J. (1994). Grounded theory methodology. Handbook of Qualitative Research, 17, pp. 273-85.

Su, Q., Shi, J-H. and Lai, S-J. (2008), 'Study on supply chain management of Chinese firms from the institutional view', International Journal of Production Economics, 115(2), 362-373.

Sun, J., Matsui, M. and Yin, Y. (2012). Supplier risk management: An economic model of P-chart considered due-date and quality risks. International Journal of Production Economics, 139(1), pp.58-64.

Tang, C. (2006). Perspectives in supply chain risk management. International Journal of Production Economics, 103(2), pp.451-488.

Tang, C. and Tomlin, B. (2008). The power of flexibility for mitigating supply chain risks. International Journal of Production Economics, 116(1), pp.12-27.

Tang, O., Nurmaya Musa, S. and Li, J. (2012). Dynamic pricing in the newsvendor problem with yield risks. International Journal of Production Economics, 139(1), pp.127-134.

Tarhini, A., Teo, T., and Tarhini, T. (2016). A cross-cultural validity of the E-learning Acceptance Measure (ElAM) in Lebanon and England: A confirmatory factor analysis. Education and Information Technologies, 21(5), pp. 1269-1282.

Thekdi, S., \& Aven, T. (2016). An enhanced data-analytic framework for integrating risk management and performance management. Reliability Engineering \& System Safety, 156, pp. 277-287.

Tomlin, B. (2006). On the value of mitigation and contingency strategies for managing supply chain disruption risks. Management Science, 52 (5), pp. 639-657.

Trkman, P., Oliveira, M. and McCormack, K. (2016). Value-oriented supply chain risk management: you get what you expect. Industrial Management \& Data Systems, 116(5), pp.1061-1083.

Tse, Y. and Tan, K. (2011). Managing product quality risk in a multi-tier global supply chain. International Journal of Production Research, 49(1), pp.139-158.

Wang, G.G., Lamond, D. and Worm, V., (2015). It's the context all the way down! An institutional theory perspective on Chinese HRM research. Journal of Chinese Human Resource Management, 6(1), pp.2-13.Waters, C. (2011). Supply chain risk management. London: Kogan Page.

Wieland, A. and Marcus Wallenburg, C. (2012). Dealing with supply chain risks. International Journal of Physical Distribution \& Logistics Management, 42(10), pp.887-905.

World Bank (2016). LPI Global Ranking. https://lpi.worldbank.org/international/ global?sort=desc\&order=LPI\%20Score\#datatable [Accessed 18.April.2018]

Wu, T., Blackhurst, J. and Chidambaram, V. (2006). A Model for Inbound Supply Risk Analysis. Computers in Industry, 57, pp.350-365.

Wu, D., Wu, D., Zhang, Y. and Olson, D. (2013). Supply chain outsourcing risk using an integrated stochastic-fuzzy optimization approach. Information Sciences, 235, pp.242258. 
Yeboah, N. E., Feng, Y., Daniel, O. S., \& Joseph, N. B. (2014). Agricultural Supply Chain Risk Identification-A Case Finding from Ghana. Journal of management and strategy, 5(2), pp. 31-48.

Zhao, L., Huo, B., Sun, L. and Zhao, X. (2013). The impact of supply chain risk on supply chain integration and company performance: a global investigation. Supply Chain Management: An International Journal, 18(2), pp.115-131.

Zsidisin, G. (2003). A grounded definition of supply risk. Journal of Purchasing and Supply Management, 9(5-6), pp.217-224.

Zsidisin, G, Melnyk, A. and Ragatz, G.L. (2005). An institutional theory perspective of business continuity planning for purchasing and supply management, International Journal of Production Research, 43 (16), pp 3401-3420.

Zsidisin, G.A., Ellram, L.M., Carter, J.R. and Cavinato, J.L. (2004). An analysis of supply risk assessment techniques. International Journal of Physical Distribution \& Logistics Management, 34 (5), pp. 397-413. 


\section{Appendix A: Questionnaire}

1. Please select the appropriate title for your position in the firm.

- CEO / Managing Director/General Manager

- Supply Chain Director/Purchasing Director/Supply Chain Manager

○ Supply Chain Operation Manager

- Purchasing/Procurement Manager

- Sourcing Manager

$\circ$ Purchasing Supervisor/Team leader

○ Purchasing Engineer/Specialist

○ Planning Manager

- Production Manager

- Warehouse Manager/Supervisor

- Logistic Manager/Supervisor

- Supplier Quality Engineer

- Others(Please state )

2. How many people are employed in your firm?

$\circ$ less than 100
○ 100 to 250
- 251 to 500
○ 501 or more

3. Please select the appropriate industry your organization belongs to.

$\circ$ Mechanical engineering

$\circ$ Automotive industry

- Electrical and electronic industry

$\circ$ Medical engineering

o Chemical industry

- Steel making and metal production

- Plastic processing

○ Furniture industry

- Processing industry

- Mold and die production, tool making

- Others(Please state)

4. Where is your firm located in China?

○ Northeast of China

- North China

- East China

- South China

- Central China

- Southwestern China

- Northwest China

$\circ$ Other areas in China mainland

- Taiwan

○ Hong Kong

5. Please indicate the level of your company's performance along the following dimensions compared to that of your competitors ( 1 - worse than competitors; 5 - better than competitors):

1) Market share

2) Sales revenue

3) Customer service level

4) Profit margin

5) Product quality

6) Order Fulfillment Lead Time

6. Supply Risk: Please indicate how well your purchasing function is able to mitigate the realization of supply risks on a 1-5 Likert scale (1-not at all; 3-fair; 5-extremely well):

1) Risks concerning the availability of products and services

2) Risks concerning late deliveries

3) Risks concerning price and costs

4) Risks concerning quality from purchasing

5) Risks related to supplier dependency 
6) Risks related to technical capability

7. Manufacturing Risk: Please indicate how well your manufacturing function is able to mitigate the realization of manufacturing risks on a 1-5 Likert scale (1-not at all; 3-fair; 5-extremely well):

1) Risks concerning production disruption

2) Risks concerning quality issues in production

3) Risks concerning inventory (e.g. high work-in-process inventory due to unreasonable manufacturing process)

4) Risks concerning market change (e.g. obsolete of product)

5) Risks related to labor (e.g.: strike, incident)

\section{Supplier orientation-}

To what extent do these statements apply to your supply chain management practices? ( $1=$ no, not at all; $3=$ partly; $5=$ yes, completely)

1) Our collaboration with supplier is evaluated regularly.

2) There are jointly formed criteria for evaluating the collaboration.

3) Suppliers are involved in developing business process.

4) There are clear objectives for the supplier relationship.

5) Both parties are actively looking for new collaborative areas.

9. Supplier dependency-

To what extent do these statements apply to your supply chain management practices? (1=no, not at all; $3=$ partly; $5=$ yes, completely)

1) There is unique knowledge that can be only utilized in certain supplier relationships (e.g. joint developed technology).

2) Specific investments are made in the collaboration and cannot be utilized elsewhere.

3) Some core activities (such as $R \& D /$ business development) of the firm are tied with suppliers

10. Systemic purchasing-

To what extent does following statement apply to your supply chain management practices? $(1=$ no, not at all; $3=$ partly; 5=yes, completely)

1) We prefer to purchase the whole service package (products and services) in an integrated manner, rather than in a separate way.

\section{Production flexibility-}

To what extent do these statements apply to your supply chain management practices? (1=no, not at all; $3=$ partly; $5=$ yes, completely)

1) Our overall production volume can be adjusted up and down efficiently.

2) Our lead times can be adjusted according to demand, either shortening or extending.

3) The product mix can be changed among different models.

12. Maturity of manufacturing process-

To what extent do these statements apply to your supply chain management practices? ( $1=$ no, not at all; $3=$ partly; $5=$ yes, completely)

1) Advance IT applications (MES, ERP) are adopt to monitor and control the operation in our firm.

2) Our production process is automated.

\section{HR management-}

To what extent do these statements apply to your supply chain management practices? $(1=$ no, not at all; $3=$ partly; $5=$ yes, completely)

1) There are continuous trainings for employee in terms of technology, skill as well as safety.

2) There are contingency plans for manufacturing disruptions related to labor, such as strike, accident or absence.

3) There is appropriate salary system as well as benefits motivating employee.

14. Customer orientation-

To what extent do these statements apply to your supply chain management practices? ( $1=$ no, not at all; $3=$ partly; $5=$ yes, completely)

1) Our supply chain management is able to response to quickly to the demand changes from the end customers.

2) Our supply chain management is able to solve supply issues, shorten lead time and speed up delivery to the end customers.

3) Our supply chain management is able to meet the expectation of the end customers

15. Maturity of supply chain risk management process-

To what extent do these statements apply to your supply chain management practices? ( $1=$ no, not at all; $3=$ partly; $5=$ yes, completely)

1) Our company has introduced a detailed supply chain risk management process.

2) We improve our risk management process on a regular basis. 
3) There is a governance structure allowing the firm to deal with risk proactively.

4) We align risk to business strategies, embed risk management principles into business planning.

16. Culture-To what extent do you agree or disagree the following statement? $(1=$ strongly disagree; $3=$ partly agree; $5=$ strongly agree)

1) Relationship (guanxi) has significant influence on the result of supply chain risk management.

2) There is an open communication culture within our firm.

3) There is an open communication culture in the supplier relationships. 